\title{
Clones Humanos: Falácias e Retrocesso em Uma Experiência Anunciada
}

Desde 1886, quando o Dr. Down descreveu a síndrome que leva seu nome, passando pelos testes de inteligência ao longo da primeira metade do século XX, a preocupação com o aprimoramento da "raça" humana se faz sentir. Na atualidade, os estudos genéticos e a possibilidade de produzir "clones" humanos ressituam a questão da eugenia. Qual a reflexão e a contribuição que a Psicologia pode apontar?

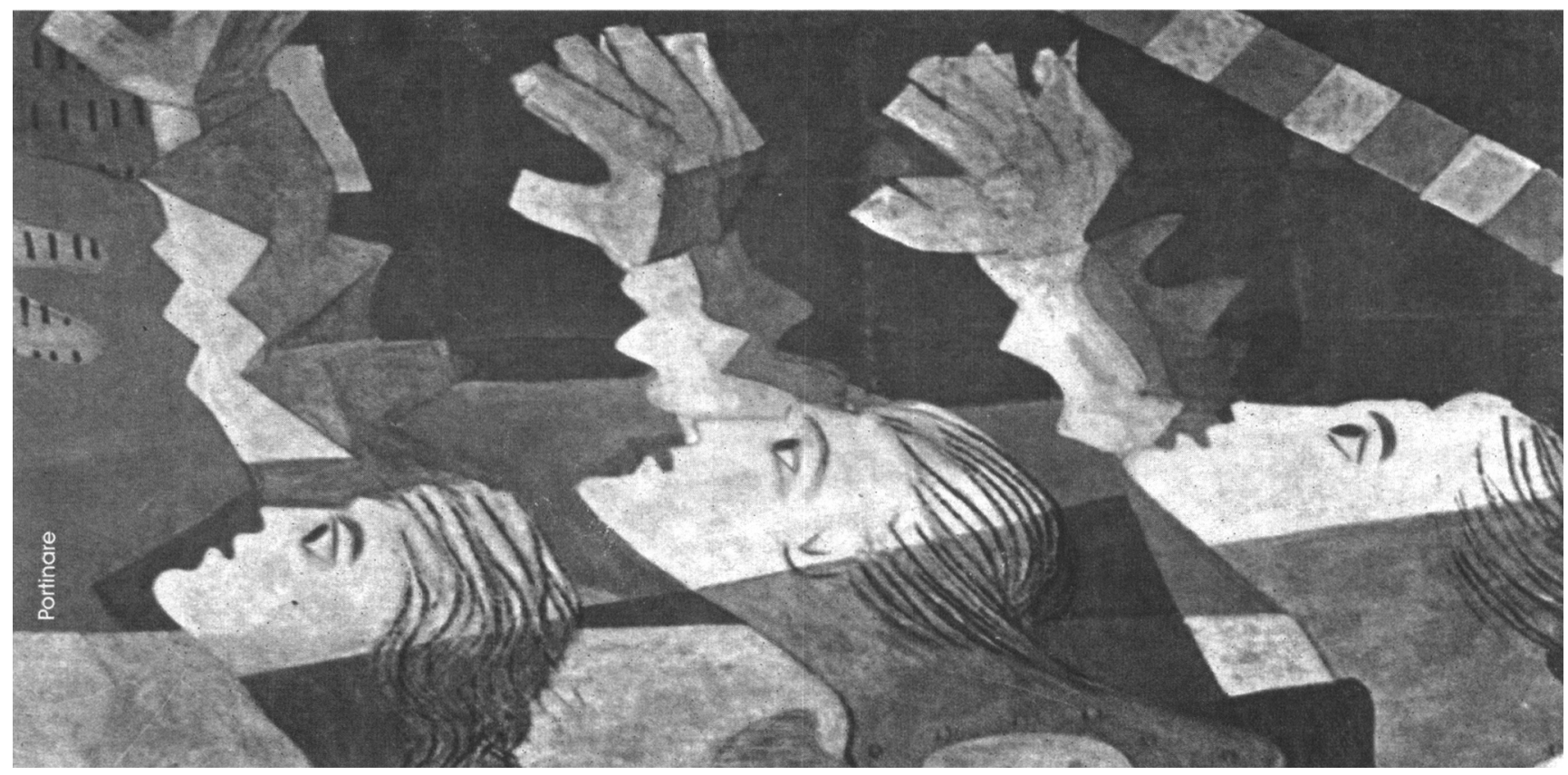

No século passado, em 1866, o Dr. John Down, conceituado médico inglês, publicava no London Medical Reports um artigo entitulado "Observaçōes acerca da classificação étnica dos idiotas" (Observations on a ethnic classification of the idiots). O Dr. Down, celebrizado por suas contribuiçōes no campo das deficiências mentais (particularmente lembrado pela referência à síndrome que hoje leva o seu nome - síndrome de Down), estava na época convencido de que as deficiências mentais resultavam de uma "suspensão" do desenvolvimento humano, a qual destinava o sujeito a um estáglo inferior da vida, isto é, às condições típıcas das raças "inferiores". Dr. Down afirmava o seu objetivo "de criar uma classificaçāo dos débeis mentais organizando-os em torno dos vários padrões étnicos - em outras palavras, construindo um sistema natural" (Gould, 1989, p. 147). Em um trecho do seu livro "O polegar do panda", Stephan Gould (1989) exemplifica as idéias do doutor:

"Down encontrou"vários exemplos nítidos da variedade etiope" e descreveu seus "olhos proeminentes", "lábios grossos" e "cabelo encarapinhado...embora nem sempre preto". "São", escreveu ele, "espécimes de negros brancos, apesar de sua ascendência européla. A seguir descreveu outros idiotas "que se organizam em torno da variedade malala" e outros que, "com testas curtas, bochechas proeminentes, olhos profundos e nariz ligeiramente simiesco", representam os povos que "originalmente habitaram o continente americano".

"Por fim, montando a escala das raças, chegou à fileira abaixo dos caucasianos, "a grande familia mongol"."Um grande número de idiotas congênitos", continuou ele, "são mongóis típicos". (p.147)

Angela Uchôa Branco

Laboratório de Microgênese das interaçōes Sociais

Instifuto de Psicologia, Universidade de Brasilla 
passado, sentiam-se, em geral, perfeitamente à vontade em expressar suas convicçōes racistas caucasianas. Entretanto, encontravam sérias dificuldades em achar explicaçōes razoáveis para a grande complexidade e sofisticação das culturas orientais.Idéias racistas, fundamentadas na superioridade genética de grupos étnicos específicos, como todos infelizmente sabemos, não se limitaram aos homens de clência do século passado. Os terríveis eventos da história mundial são mais eloqüentes do que qualquer anállse intelectual do tema. Mas é preciso recordar que na Psicologia, por exemplo, tais pressupostos estiveram na própria origem e desenvolvimento do estudo da "inteligência". Os cientistas responsáveis pela criação e ampla utilização dos testes psicológicos de "inteligência" ao longo de todo o século XX, particularmente até a II Grande Guerra, acreditavam que os testes eram capazes de "provar" os seus argumentos acerca das capacidades inatas dos indivíduos. Grande parte destes senhores seguiam ( ou ainda seguem), de forma mais ou menos explícita, as idélas de Sir Galton, que na segunda metade do século passado fundou o movimento eugênico. A eugenia, como sabemos, evoca argumentos aos quais atribue um caráter "científico" para apregoar a necessidade do aprimoramento (ou purificação) da raça humana.

Um exemplo disto nos é dado pelo famoso estatístico Karl Pearson. O Prof. Pearson, após um discurso acerca da neutralidade da ciência em um de seus artigos, sugeriu que os judeus bons, honestos e corajosos foram exterminados pelos czares, e que somente a ralé sobreviveu! Em seguida, apresentou dados demonstrando como as crianças judias russas e polonesas eram inferiores, dados que lam dos dentes da criança à sua inteligência, argumentando sobre a necessidade de se impedir a imigração de uma raça por ele considerada como "parasitica". Afirmava, em seu discurso, que "nenhum comprador de gado compraria todo um rebanho só porque espera encontrar um ou dois espécimes ótimos ali incluídos.." (Eysenck \& Kamin, 1982, p. 181). Nos Estados Unidos, Lewis Terman, um dos importantes autores responsáveis pela elaboração de testes de inteligência, sugeriu a criação de classes especiais para filhos de imigrantes latinos, que, segundo ele, apenas serviam para trabalhar como operários sem qualificação. Dr. Terman chegou a insinuar que a sociedade deveria evitar que tais imigrantes se reproduzissem. Idélas como estas deram origem e fundamentaram várias medidas concretas de ordem política, tais como a lel de esterlização compulsória de criminosos e de outros "degenerados", promulgada em 1907 no estado de Indlana, nos EUA (Eysenck \& Kamin, 1982). Durante a I Guerra, a aplicação de testes de inteligêncla indicaram que os emigrantes ingleses, canadenses e escandinavos eram "superiores" aos russos, poloneses e italianos, o que deu origem à restrição, em 1924, da imigração para os EUA dos "geneticamente inferiores do sudeste e leste europeus". Recente reportagem da Revista Veja (de 3/9/97) revela, para nosso espanto, que alguns países europeus, como Suécia, Dinamarca, Bélgica etc., mesmo depois da II Guerra Mundial e até bem pouco tempo, praticavam a esterilização de milhares de pessoas consideradas deficientes ou incapazes por alguma razāo, colocando em prática os fundamentos da eugenia!

De volta à esfera da Psicologia, em 1969 Arthur Jensen afirmou, em coro com vários colegas, que $80 \%$ da inteligência é de origem genética (Eysenck \& Kamin, 1982). Argumentou que, conforme os testes demonstram, os negros são inferiores aos brancos, afirmando também que programas educacionais de natureza compensatória estão fadados ao insucesso. Tais programas são, de fato, questionáveis, porém por razōes de ordem totalmente diversa (ver, por exemplo, Kramer, 1982). Mais recentemente, e seguindo a mesma linha equivocada de raciocínio, Eysenck sugeriu que os negros "altivos" foram eliminados ao longo da história (Eysenck \& Kamin, 1982). Para Eysenck, porém, diferentemente do Prof. Pearson, são os judeus que constituem uma raça especial: o seu QI médio apresenta-se em torno de 118, e isto explicaria o fato de terem os judeus recebido mais prêmios Nobel que os demais indivíduos. Favorável à diferenciação dos grupos étnicos quanto à inteligêncla, Eisenck se pergunta por que entram mais judeus, chineses e Japoneses nas universidades, esquecendo-se de considerar as grandes diferenças culturais que caracterizam os vários grupos humanos. Eysenck acaba propondo a necessidade de uma espécie de eugenia, para evitar que ocorra uma queda geral no Ql das populaçōes humanas, pois, segundo ele, os indivíduos de mais baixo $Q I$ tendem a se proliferar mais.

Os defensores da utilização dos testes de inteligêncla, de fato, acreditam que esta se traduza em um conjunto de capacidades universais, mensuráveis através de instrumentos culturalmente "neutros". E muitos daqueles que os utilizam acreditam também que a inteligência é em grande parte determinada por fatores hereditários, utilizando-os, portanto para realizar estudos com tal objetivo. É preciso lembrar, porém, que os testes surgiram da necessidade socialmente criada de medir e quantificar, para objetivos práticos, a capacidade de resolver problemas e adquirir conhecimentos. Apesar de progressivos esforços, os testes acabam por refletir, naturalmente, o background cultural daqueles que os elaboram. Os testes de desempenho intelectual, por exemplo, tomam quase sempre como referência habilidades, aptidōes e 
conhecimentos típicos nas escolas de classe média do mundo ocidental (Bronfenbrenner, 1989; Carraher, Carraher, \& Schliemann, 1988 ). Os pesquisadores que os utilizam, portanto, assumem que tais habilidades e conhecimentos representam um critério para avaliar aptidōes que seriam, segundo eles, de relevâncla universal. Autores contemporâneos, de diferentes orientaçōes teóricas, entretanto, cada vez mais elaboram suas definiçōes de "inteligência" levando em conta o contexto físico e sócio-cultural em que o indivíduo se insere, e cujos problemas específicos precisa resolver em seu processo de adaptação (Ades, 1986; Bronfenbrenner, 1989; Carraher, 198 ; Cole, 1992)

Utlizando testes, no entanto, multos estudos foram reallzados para determinar quantitativamente $o$ papel dos genes sobre o desenvolvimento humano, particularmente estudos comparando o desempenho intelectual, e várlas outras características psicológicas, de gêmeos monozigóticos e de outros indivíduos com diferentes graus de parentesco entre si (Cole \& Cole, 1993). Estudos comparando crianças adotadas e as suas famíllas (blológica e de adoçāo) foram, também, muito populares neste campo de pesquisa. Quase todos os estudos, porém, tem apresentado sérlas deficlências ou mesmo vieses metodológicos que dificultam qualquer tıpo de conclusão (a não ser, é claro, que muitas vezes os clentistas "provam" exatamente aquilo que desejam demonstrar...).

o fato de fatores como aprendizagem e experiência subjetiva não permitirem ao investigador controlar os seus efeitos constitui um sério problema para esse tipo de investigação. São muitos os resultados contraditórios, e a simples constatação de que os genes exercem certo impacto sobre algumas características ou habilidades psicológııcas não significa que sejam eles os principals determinantes do seu desenvolvimento e plena expressão nos seres humanos. A crença nos testes de QI como Indicadores de capacidades inatas, entretanto, era tāo arraigada entre clentistas e lelgos que somente em 1975 o Conselho de Questōes Científicas da APA (American Psychological Association) rejeltou 0 teste de inteligêncla como sendo um Instrumento capaz de medir uma "capacidade ou potencial" nāo adquirido!

Mas afinal, o que tudo isto tem a ver com a produção de clones humanos? Absolutamente tudo, uma vez que se trata do poder atribuído aos genes para determinar características dos seres humanos. Iniclalmente, porém, é preciso perguntar: Qual o objetivo em produzir clones humanos? $O$ que justificaria tal experiêncla? A produção de seres especials, com habllidades ou funçōes especlals para cumprir missōes especificas no contexto de uma sociedade de mercado? Eugenla, para "melhorar" a qualidade da espécle em geral? Valdade humana, mais um Item para o consumo frenético dos poderosos? Ou apenas uma brincadeira Irresponsável, fruto da mera curiosidade?

Seja qual for a razâo que venha a motivar os seres humanos a produzir exemplares geneticamente idênticos a sı mesmos, esta tem como base ou fundamento uma grande falácia, qual seja, a de acreditar que isto representarla alguma espécie de avanço ou evoluçāo. Idélas como esta exigem que se discuta seriamente o sentido ético e moral que assumimos diante da própria vida. Em minha opiniào, experiências desta natureza vem a ferir de forma profunda os mais significativos valores humanos, Já tão dissolvidos e descaracterizados pelo turbilhão da ditadura econômica deste final de século, e pela terrivel realidade de uma globalização pautada exclusivamente no ideal capitalista do neoliberalismo.

Com um pouco da história do estudo da inteligência, procuramos exemplificar o quanto a crença nos genes como fatores fundamentals e constitutivos da personalidade humana fol, e alnda continua sendo, influente em nosso amblente cultural. Trata-se de uma crença arralgada ao pensamento de multos, pelas razōes mais diversas. Minha contribuição, como pesquisadora e estudante da Psicologla humana tem por objetlvo, em primelro lugar, alertar para os perigos concretos de tal tecnologla, pois conforme apontamos nas questōes acima, multas podem ser as motlvaçōes para se tentar a clonagem humana, apesar da maloria, talvez, concordar com a sua insensatez. Em segundo lugar, é preciso informar as pessoas acerca dos conhecimentos produzldos na esfera científica da Psicologla e seus recentes avanços teóricos, particularmente no campo dedicado ao estudo do desenvolvimento.

Eis aqul alguns pontos para reflexão: sabemos que a característica essencial do desenvolvimento humano é que este resulta de um processo de interação entre fatores genéticos e amblentais. É Interessante notar que, em geral, nos textos de Psicologia, a referência aos genes vem sempre em primeiro lugar. Talvez isto indlque para algumas pessoas que estes tem uma certa primazla ou precedência, e que o amblente sirva apenas para modular os seus efeltos gerals sobre o desenvolvimento. Este não é absolutamente o caso. Os efeltos da interação entre os fatores não são quantificávels a partir da perspectiva sistêmica que cada vez mals vem sendo adotada para a explicação dos fenômenos associados à vida, ou seja, fenômenos relativos ao desenvolvimento dos organismos vivos. A teoria sistêmica (Bertalanffy, 1977; Ford \& Lerner, 1992), que adota modelos de causalldade múltipla em contraposição a modelos de causalidade linear, vem progressivamente 
orientando o pensamento teórico da Psicologia, em especial nos estudos do desenvolvimento humano (Fogel, 1993; Ford \& Lerner, 1992).

Além disso, o contexto sócio-histórico cultural tem deixado de ser encarado como uma simples variável a mais a ser investigada, passando a ser considerado o fator básico, essencial, da própría constituição do indivíduo, sua personalidade, sua subjetividade (Cole, 1992). Segundo uma perspectiva sócioconstrutivista, este processo de constituição se dá de forma bilateral, isto é, o indivíduo inserido no contexto é constituído ao mesmo tempo em que ativamente constitui a cultura. Este continuamente reelabora as mensagens e significados recebidos sob a forma de hábitos, crenças $\mathrm{e}$ valores, e introduz novos elementos e significados no contexto da cultura em que vive. Isto tudo se traduz na idéia de que o desenvolvimento humano implica em certo grau de determinação, mas também continua sendo em grande e significativa parte um processo indeterminado (Valsiner, 1987, 1997; Fogel, Lyra \& Valsiner, 1997).

Segundo o modelo proposto por histórico cultural tem deixado de ser encarado como uma simples variável a mais a ser

investigada, passando a ser considerado o fator básico

essencial, da própria constituição do indivíduo, sua personalidade, sua subjetividade (Cole, 1992). Waddington (Valsiner, 1987) para explicar o desenvolvimento dos seres vivos (ou sistemas abertos), diferenças relativamente pequenas ocorrendo em momentos críticos de decisão podem implicar em reorientaçōes consideráveis no curso desenvolvimental. Sendo assim, cada indivíduo resulta único $\mathrm{e}$ singular, pois sua história de interaçōes ao longo da vida é absolutamente pessoal e intransferivel. Isto se aplica mesmo a gêmeos monozigóticos vivendo na mesma família. Os psicólogos sāo às vezes questionados acerca de sua insistência sobre a importância fundamental do ambiente. Perguntase porque filhos do mesmo pai e da mesma mãe vivendo juntos são tão diferentes, se o ambiente é o mesmo. Esquece-se, no entanto, de considerar as profundas diferenças no tratamento, nas preferências, enfim, nos papéis específicos que cada filho vai assumindo como membro daquela família, em relação a cada um dos pais, e em relação um ao outro.

Não podemos esquecer que "ambiente" é um termo demasiado genérico, que na verdade inclui diferentes niveis sistemicamente organizados (Bronfenbrenner, 1989) que vão desde o contexto imediato ao contexto mais amplo como o nível sócio-econômico ou a civilização ocidental, por exemplo. Além disso, o mesmo evento ou eventos tem um impacto diferente a depender das interaçōes que ocorrem entre o evento e as características biológicas do sujeito (Ford \& Lerner, 1992). O impácto também será diferente a depender do contexto geral e do momento de desenvolvimento em que se encontra a criança quando ocorre o evento, como explica Vygotsky (1929/1994).

Em entrevista publicada na revista Veja de 17 de setembro de 1997, Edward Wilson, fundador da sociobiologia (ciência conhecida entre nós como defensora do papel fundamental exercido pelos genes na determinação do comportamento social) expressou de forma extremamente clara, sintética e objetiva como a questāo da clonagem humana deve ser entendida. Após o repórter haver lhe sugerido que muitas pessoas gostariam de deixar uma cópia de si mesmos ao morrer, ele afirma:

"É uma estupidez. Em primeiro lugar, o clone é uma outra pessoa. Um clone pode roubar a namorada e os bens do sujeito que lhe serviu de molde. Pode até matar o seu molde. A fabricaçāo de clones não vai popularizar-se, não vai tornar-se procedimento corriqueiro, pois isso não interessa a ninguém. Hoje, as técnicas da medicina permitem aos casais produzir quantos gêmeos idênticos desejarem e nem por isso o número de gente igual no mundo aumentou. De que adianta um ditador, como se chegou a temer, mandar fazer um clone de si mesmo? Um clone de Saddam Hussein pode ser educado na Suiça e tornar-se um grande pianista. Os genes não são tudo. Genes são apenas parte da entidade que chamamos de ser humano. O que interessa, no fundo, é como a pessoa será criada, que tipo de educação receberá. A maneira como ela foi concebida $e$ o potencial genético que trouxe ao mundo contam muito pouco. $\dot{E}$ bom pensar na clonagem humana como mais uma tentativa fracassada de ressuscitar a eugenia, o aprimoramento artificial da raça humana que tanto fascínio exerceu nos meios totalitários no passado."

A biodiversidade e a variabilidade, defendidas pelo Dr. Wilson nesta entrevista, são consideradas como elemento importante $e$ essencial aos processos de adaptaçào. Além de ser este um argumento facilmente compreensivel pelo senso comum, consiste em tese defendida, talvez por unanimidade, por todos os setores da ciência atual. Segundo os cálculos de Scheinfeld (1972, citado em Cole \& Cole, 1993), a probabilidade da ocorrência de uma combinação especifica de genes é da ordem de um em trilhões. Manter a variabilidade e promover a heterogeneidade e a diversidade é, portanto, fundamental para garantir a sobrevivência e o desenvolvimento da própria vida neste planeta. Mas é também importante que a garantia desta diversidade $e$ heterogeneidade não se restrinja, apenas, ao nível genético, mas que se estenda ao nivel das idéias, da cultura e das próprias sociedades, pois esta talvez seja a única maneira eficaz de evitar que, no futuro, tenhamos que conviver com a hegemonia e os perigos do etnocentrismo e do conservadorismo político-ideológico. Etnocentrismo que sustenta, como Eisenck o faz, a inevitabilidade da divisão da sociedade em classes sociais intrinsecamente distintas. 
claramente se posicionando a favor do agravamento da intolerância e da injustiça social.

Procurando encontrar razões mais nobres para a clonagem humana, Fermin Schramm (1997) pondera, em seu artigo na revista Clência Hoje, sobre a necessidade de cautela acerca das questōes relacionadas à clonagem humana, e argumenta sobre a conveniência ou não de preservarmos o patrimônio genético de seres especiais, como por exemplo, seres mais resistentes a doenças ou a radiaçōes. É o caso de aqui nos perguntarmos sobre as perigosas conseqüências de concepçōes como esta, que vão desde o plano psicológico ao da organização sócio-política das sociedades. É o caso, principalmente, de questionarmos: afinal, quais são as nossas priorldades? Quais são as principais e mais graves questōes que os seres humanos estão, no momento, necessitando enfrentar? Não há dúvidas de que os problemas que mais nos afligem não estão situados no plano da genética ou da sobrevivência individual, mas sim no plano da sobrevivência das próprias sociedades humanas como um todo. Tais problemas remetem a sérias questōes de ordem econômica, política, social, a questões relacionadas ao trabalho, à distribuição de riqueza, à exclusāo social, ao acesso à informação, enfim, todas essas questões envolvendo os princípios éticos e morais que precisam nortear os caminhos a seguir.

Impressiona o nível de descaso e intolerância, de desrespeito e desconsideração entre indivíduos e entre grupos humanos. Impressiona que individuos e grupos, ao invés de encontrarem na pluralidade, e na diversidade, recursos inestimáveis para a construçāo de soluçōes criativas de caráter global, busquem simplesmente a eliminação uns dos outros, em um contínuo esforço competitivo para banir a diferença e construir, cada qual, o seu império particular às custas do outro. Temas como justiça, tolerância, igualdade de oportunidades, e a busca de modelos que preservem e promovam os ideais de igualdade, fraternidade e liberdade, estes sim, é que mereceriam a meu ver, e com urgência absoluta, ocupar o centro das preocupaçōes de todos nós.

Ades, C. (1986) Entre eidilos exenedrins: experiência e pré-programas no comportamento humano. Em: CRP (6a Região) SPESP (Ed.) Psicologia no ensino de segundo grau: uma proposta emancipadora. São Paulo:

EDICON.Bertalanffy, L. (1977). Teoria geral dos sistemas. Petrópolis: Ed. Vozes.

Bronfenbrenner,U. (1989). Interacting systems in human development.

Research paradigms: Present and future. In N. Bolger, A. Caspi, G. Downey, \& M. Moorehouse (Eds), Persons in contexts: Developmental processes (p. 25-49).

Cambridge: Cambridge University Press.

Carraher, T. , Carraher, D., \& Schliemann, A. (1988). Na vida dez; na escola zero - os contextos culturais da aprendizagem de matemática.São Paulo: Cortez.

Cole, M. (1992). Culture in development. Em: M.H.

Bornstein \& M.E. Lamb (orgs) Developmental psychology: An advanced text book (pp.731-788).

New Jersey: Lawrence Erlbaum Associates Publishers. Cole, M. \& Cole, S. (1993). The development of children. New York: Freeman and Company.

Eysenck, H.J. \& Kamin, L. (1982) O grande debatè sobre $a$ inteligência. Brasília: Editora Universidade de Brasília.
Fogel, A., Lyra, M., \& Valsiner, J. (1997). Dynamics and indeterminism in developmental and social processes. Hillsdale, NJ: Lawrence Erlbaum Ass.Ford, D. H. \&

Lerner, R. M. (1992). Developmental systems theory: An integrative approach. London: Sage Publications.

Gould, S.J. (1989). O polegar do panda: reflexöes sobre história natural. São Paulo: Martins Fontes Ed.

Kramer, S. (1982). A politica do pré-escolar no Brasil. Rio de Janeiro: Achiamé.

Schramm, F.R. (1997). O caso Dolly: até aonde a clonagem pode chegar.SBPC: Ciência Hoje, 22, 127, 3442.

Valsiner, J. (1989). The social nature of human development: Some preliminaries. Em: J. Valsiner, Human development and culture: Thesocial nature of personality and its study (pp. 1-16). Lexington, MA: Lexington Books.

Valsiner, J. (1997). Culture and the development of children's action. NY: John Wiley \& Sons.

Vygotsky, L. (1929/1994). The problem of the environment. Em: R. Van der Deer \& J. Valsiner (Eds), The Vygotsky reader (pp. 338-354). Oxford, UK: Basil Blackwell Ltd.
Referências bibliográficas 